\title{
X-ray flux and x-ray burnthrough experiments on reduced-scale targets at the NIF and OMEGA lasers (paper)
}

M.B. Schneider, D.E. Hinkel, B.K. Young, J.P. Holder, A.B. Langdon, H.A. Baldis, R. Bahr, D.E. Bower, H.C. Bruns, K.M. Campbell, J.R. Celeste, S. Compton, C.G. Constantin, R.L. Costa, E.L. Dewald, S.N. Dixit, M.J. Eckart, D.C. Eder, M.J. Edwards, A.D. Ellis, J.A. Emig, D.H. Froula, V. Glebov, S.H. Glenzer, D. Hargrove, C.A. Haynam, R.F. Heeter, M.A. Henesian, G. Holtmeier, D.L. James, K.S. Jancaitis, D.H. Kalantar, J.H. Kamperschroer, R.L.Kauffman, J.Kimbrough, R. Kirkwood, A.E. Koniges, O.L. Landen, M. Landon, F.D. Lee, B.J. MacGowan, A.J. Mackinnon, K.R. Manes, C. Marshall, M.J. May, J.W. McDonald, J. Menapace, S.J. Moon, E.I. Moses, D.H. Munro, J.R. Murray, C. Niemann, D. Pellinen, K. Piston, G.D. Power, V. Rekow, S. Roberts, J.A. Ruppe, J. Schein, et al.

\section{August 29, 2005}

Inertial Fusion Science and Applications 2005 Biarritz, France September 4, 2005 through September 9, 2005 
This document was prepared as an account of work sponsored by an agency of the United States Government. Neither the United States Government nor the University of California nor any of their employees, makes any warranty, express or implied, or assumes any legal liability or responsibility for the accuracy, completeness, or usefulness of any information, apparatus, product, or process disclosed, or represents that its use would not infringe privately owned rights. Reference herein to any specific commercial product, process, or service by trade name, trademark, manufacturer, or otherwise, does not necessarily constitute or imply its endorsement, recommendation, or favoring by the United States Government or the University of California. The views and opinions of authors expressed herein do not necessarily state or reflect those of the United States Government or the University of California, and shall not be used for advertising or product endorsement purposes. 
The headers will be insert by the Publisher

The headers will be insert by the Publisher

The headers will be insert by the Publisher

\title{
$X$-ray flux and X-ray burnthrough experiments on reduced- scale targets at the NIF and OMEGA lasers
}

M. B. Schneider ${ }^{1}$, D. E. Hinkel ${ }^{1}$, B. K. Young ${ }^{1}$, J.P. Holder ${ }^{1}$, A.B. Langdon ${ }^{1}$, H.A. Baldis ${ }^{2}$, R. Bahr', D.E. Bower ${ }^{1}$, H.C. Bruns ${ }^{1}$, K.M. Campbell ${ }^{1}$, J.R. Celeste $^{1}$, S. Compton ${ }^{1}$, C.G. Constantin ${ }^{2}$, R.L. Costa ${ }^{1}$, E. L. Dewald ${ }^{1}$, S.N. Dixit $^{1}$, M.J. Eckart ${ }^{1}$, D.C Eder ${ }^{1}$, M.J. Edwards ${ }^{1}$, A.D. Ellis ${ }^{1}$, J.A. Emig ${ }^{1}$, D.H. Froula $^{1}$, V. Glebov ${ }^{3}$, S.H. Glenzer ${ }^{1}$, D. Hargrove ${ }^{1}$, C.A. Haynam ${ }^{1}$, R. F. Heeter $^{1}$, M.A. Henesian ${ }^{1}$, G. Holtmeier ${ }^{1}$, D.L. James ${ }^{1}$, K.S. Jancaitis ${ }^{1}$, D.H. Kalantar $^{1}$, J.H. Kamperschroer ${ }^{1}$, R.L.Kauffman ${ }^{1}$, J.Kimbrough ${ }^{1}$, R. Kirkwood ${ }^{1}$, A.E. Koniges ${ }^{1}$, O.L. Landen ${ }^{1}$, M. Landon ${ }^{1}$, F.D. Lee ${ }^{1}$, B.J. MacGowan ${ }^{1}$, A.J. Mackinnon $^{1}$. K.R. Manes ${ }^{1}$, C. Marshall ${ }^{1}$, M.J. May ${ }^{1}$, J.W. McDonald ${ }^{1}$, J. Menapace $^{1}$, S.J. Moon ${ }^{1}$, E.I. Moses ${ }^{1}$, D.H. Munro ${ }^{1}$, J.R. Murray ${ }^{1}$, C. Niemann ${ }^{1}$, D. Pellinen ${ }^{4}$, K. Piston ${ }^{1}$, G. D. Power ${ }^{1}$, V. Rekow ${ }^{1}$, S. Roberts ${ }^{3}$, J.A. Ruppe ${ }^{1}$, J. Schein ${ }^{1}$, W. Seka ${ }^{3}$, R. Shepherd ${ }^{1}$, M.S. Singh ${ }^{1}$, C. Sorce, P.T. Springer $^{1}$, C.H. Still ${ }^{1}$, C. Stoeckl ${ }^{3}$, L.J. Suter ${ }^{1}$, G.L. Tietbohl ${ }^{1}$, R.E. Turner ${ }^{1}$, B.M. Van Wonterghem ${ }^{1}$, R.J. Wallace ${ }^{1}$, A. Warrick ${ }^{1}$, P. Watts ${ }^{4}$, F. Weber ${ }^{1}$, P.J. Wegner ${ }^{1}$, E.A. Williams ${ }^{1}$, P.E. Young ${ }^{1}$

${ }^{1}$ Lawrence Livermore National Laboratory, 7000 East Avenue, Livermore, CA 94550

${ }^{2}$ University of California at Davis, One Shields Avenue, Davis, CA 95616, USA

${ }^{3}$ Laboratory for Laser Energetics, 250 East River Road, Rochester, NY 14623-1299, USA

${ }^{4}$ Bechtel Nevada Corporation, Livermore, CA, USA 94550

\begin{abstract}
An experimental campaign to maximize radiation drive in small-scale hohlraums has been carried out at the National Ignition Facility (NIF) at the Lawerence Livermore National Laboratory (Livermore, CA USA) and at the OMEGA laser at the Laboratory for Laser Energetics (Rochester, NY USA). The small-scale hohlraums, laser energy, laser pulse, and diagnostics were similar at both facilities but the geometries were very different. The NIF experiments used on-axis laser beams whereas the OMEGA experiments used 19 beams in three beam cones. In the cases when the lasers coupled well and produced similar radiation drive, images of x-ray burnthrough and laser deposition indicate the pattern of plasma filling is very different.
\end{abstract}

\section{Introduction}

Our program[1-3] seeks to use high power lasers to extend hohlraum performance to higher radiation temperatures. This is accomplished by putting all the available laser energy into as small a hohlraum as possible in as short a time as possible. The result is a hot cavity filled with high $\mathrm{Z}$ plasma and $\mathrm{x}-$ 
radiation, a "hot hohlraum". Hot hohlraum performance is limited by the hot wall material ablating and filling the can with plasma. The laser interacts with this plasma[1-4] outside and inside the can limiting laser-hohlraum coupling. In this paper, we study hohlraum performance vs laser geometry.

\section{The Experiment}

Experiments were performed at the NIF laser in Livermore, CA, USA [5] and the OMEGA laser in Rochester, NY, USA [6]. About $9.5 \mathrm{~kJ}$ of $351 \mathrm{~nm}$ laser energy in $1 \mathrm{~ns}$ (OMEGA) or 1.1ns (NIF) flattop pulses were incident into reduced-scale hohlraums. Figure 1 shows the geometry and the hohlraum.

Figure 1. Experimental geometry and target. At NIF, four laser beams are incident along hohlraum axis. At OMEGA, 19 laser beams are incident in 3 cone angles $\left(23^{\circ}, 48^{\circ}, 59-62^{\circ}\right)$. The targets were $3.5 \mu \mathrm{m}$ thick $\mathrm{Au}$ cans with large $\mathrm{Pb}$-doped plastic shields around the laser entrance hole (LEH). The shields were coated with $4 \mu \mathrm{m}$ parylene. The $50 \mu \mathrm{m}$ diameter holes in hohlraum wall allowed x-rays to be detected by
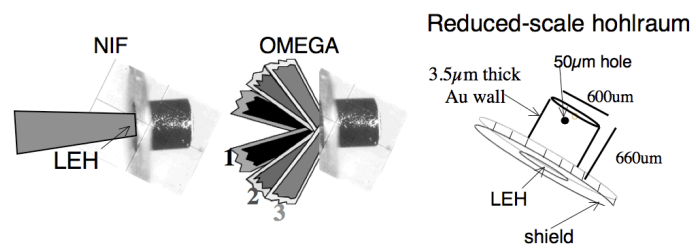
diagnostic at onset of laser pulse.

At NIF, the laser beams were conditioned with small phase plates and polarization smoothing crystals[1,2]. At OMEGA, the beams expand with $\mathrm{f} / 6.7$ so the six $23^{\circ}$ beams were defocused by $1.8 \mathrm{~mm}$, the six $48^{\circ}$ beams were defocused by $-2.2 \mathrm{~mm}$, and the $\sim 60^{\circ}$ beams had distributed polarization rotator plates (DPRs)[7] (five), or 100 $\mu \mathrm{m}$ small phase plates (two).

The x-radiation coming out of the LEH is measured with a low spectral resolution, but absolutely calibrated spectrometer called DANTE. At NIF, DANTE[8] has eighteen channels : 3 mirror+filter combinations in front of an $\mathrm{x}$-ray diode for channels in the $100-500 \mathrm{eV}$ x-ray range plus 15 filter plus $\mathrm{x}$-ray diode for channels in the $600-10000 \mathrm{eV}$ x-ray range. At OMEGA[9], DANTE had ten channels : 3 mirror+filter channels and 7 filter channels covered the $600-3000 \mathrm{eV}$ x-ray range. The DANTE views the LEH at $21.8^{\circ}$ to the hohlraum axis at NIF and at $41.8^{\circ}$ at OMEGA.

Timed-pinhole images at $\mathrm{x}$-ray energies of $\sim 10 \mathrm{keV}$ and $1 \mathrm{keV}$ were taken with a soft $\mathrm{x}$-ray snout mounted to a four-strip microchannel plate (MCP) framing camera. The snout is similar to previous designs[10] but had four (not two) mirror+filter channels and one straight-through channel. It produced four soft x-ray images $(\sim 1 \mathrm{keV})$ separated by $\sim 50 \mathrm{ps}$ and one hard x-ray image per MCP strip. Images recorded in hard $\mathrm{x}$-rays $(\sim 10 \mathrm{keV})$ transmitted through the $3.5 \mu \mathrm{m}$ thick gold wall show the laser deposition region. Images recorded in soft x-rays show the glowing outside wall. The X-radiation inside the can heats the inner wall, and the heat diffuses through the wall in a Marshak heat wave[11]. The time it takes to heat a wall of known thickness is the x-ray burnthrough time[11]. The targets had a large shield around the laser entrance hole (LEH) (Figure 1) to prevent the DANTE spectrometer from seeing the glowing of the outside walls.

\section{Results}

X-radiation fluence as measured by DANTE is shown in Figure 2. Within the error, both targets produce similar fluences (but different time dependences). Backscatter is about $15 \%$ [1]. 

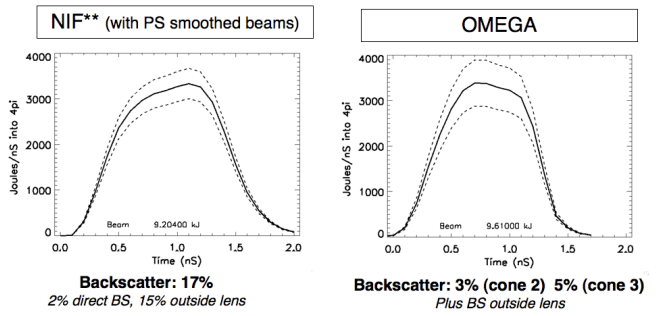

Figure 2. DANTE results on radiation drive: Both targets reached the same fluence $(\sim 3300$ Joules/ns into $4 \pi$ ), corresponding to $\mathrm{T}_{\mathrm{rad}} \sim 327 \mathrm{eV}$. The DANTE views the bright laser spot(s), whose position in time is a function of the plasma filling. Fluence peaked at end of pulse for NIF target and at $\sim 0.5 \mathrm{~ns}$ for OMEGA target.

Pinhole images from NIF experiments are compared to LASNEX simulations [1,2] in Figure 3.

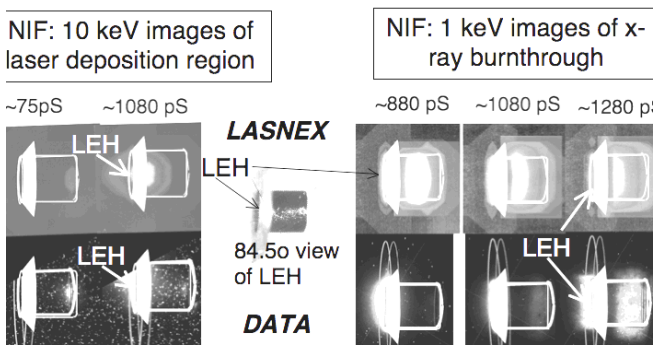

Figure 3. NIF Images of LASNEX simulations and data: View is $84.5^{\circ}$ into LEH. $10 \mathrm{keV}$ LASNEX simulations predict laser spot moves to LEH by 1080ps but data still sees some spot reaching back wall. $1 \mathrm{keV}$ LASNEX simulations show bright burnthrough occurs near front of can at $\sim 880$ ps but data shows burnthrough beginning at $\sim 880$ ps near back of can and is very bright at $\sim 1280$ ps.

Pinhole images from OMEGA experiments are shown in Figure 4. The $10 \mathrm{keV}$ images show the lasers deposit their energy near the LEH (the interior of the hohlraum is near or above critical density) and the burnthrough occurs near the LEH. At NIF, burnthrough occurs first near the back wall, and the $10 \mathrm{keV}$ images indicate laser beams can still reach the back wall. Thus, the OMEGA targets fill faster than the NIF targets, which helps explain the time behavior of the x-ray fluences.

Figure 4. OMEGA images of data (view is $37.4^{\circ}$ to back wall): Time is given in ps. $10 \mathrm{keV}$ images show laser deposition åregion moves from back wall towards LEH; $\quad 1 \mathrm{keV}$ images show $\mathrm{x}$-ray burnthrough occurs first near LEH.
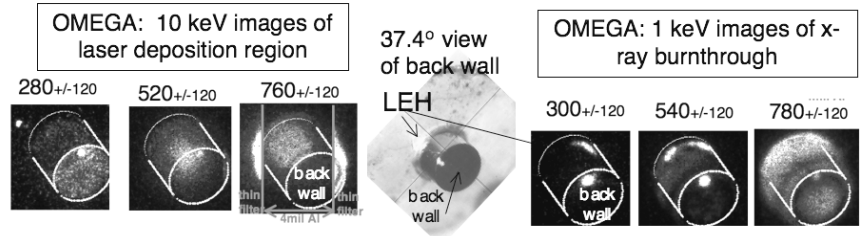

\section{Acknowledgments}

We thank the NIF and OMEGA staff for their excellent work, expertise, insight, and patience. Work performed under the auspices of the U.S. Department of Energy by the Lawrence Livermore National Laboratory under Contract No. W-7405-ENG-48 and grant number DE-FG52-2005NA26017 (NLUF).

\section{References}

[1] D. E. Hinkel M. B. Schneider, H. A. Baldis, et al., Phys. Plasmas, 12, 056305, (2005)

[2] D. E. Hinkel et al., These proceedings

[3] H.A. Baldis, C.G. Constantin, M.B. Schneider et al., These proceedings

[4] A.B. Langdon and D.E. Hinkel, Phys. Rev. Lett. 89, 015003 (2002)

[5] G.H. Miller, E.I. Moses and C.R. Wuest, Nucl. Fusion 44 S228 (2004).

[6] T. R. Boehly, R. S. Craxton, T. H. Hinterman, J. H. Kelly, et al., Rev. Sci. Instrum. 66, 508 (1995)

[7] T.R. Boehly, V.A. Smalyuk, D.D. Meyerhofer, et al., J. Appl Physics 853444 (1999)

[8] E.L. Dewald, et al., Rev. Sci. Instrum. 75, 3759 (2004)

[9] H.N. Kornblum, R.L. Kauffman, and J.A. Smith, Rev. Sci. Instrum. 57, 2179 (1986)

[10] F. Ze, R. L. Kauffman, J. D. Kilkenny, et al., Rev. Sci. Instrum, 63, 5124 (1992)

[11] J. Hammer and M. Rosen, Phys. Plasmas, 10, 1829, (2003) 